\title{
Randomised trial of mefenamic acid versus tranexamic acid in management of menorrhagia
}

\author{
Madhu J. ${ }^{1 *}$, Shylaja A. S. ${ }^{2}$ \\ ${ }^{1}$ Department of Obstetrics and Gynecology, Karnataka Institute of Medical Sciences, Hubli, Karnataka, India \\ ${ }^{2}$ Department of Obstetrics and Gynecology, St. Philomena's Hospital, Viveknagar, Bengaluru, Karnataka, India
}

Received: 09 August 2017

Accepted: 04 September 2017

\section{*Correspondence:}

Dr. Madhu J.,

E-mail: madhuobg@yahoo.co.in

Copyright: (c) the author(s), publisher and licensee Medip Academy. This is an open-access article distributed under the terms of the Creative Commons Attribution Non-Commercial License, which permits unrestricted non-commercial use, distribution, and reproduction in any medium, provided the original work is properly cited.

\begin{abstract}
Background: The objective of the study was to compare the efficacy of mefenamic acid, a non-inflammatory drug with tranexamic acid, an antifibrinolytic drug in management of menorrhaghia.

Methods: Randomised trial of women attending outpatient department of St. Philomena's hospital, Bangalore with complaints of menorrhagia. Fifty four patients with complaints of menorrhagia were randomly assigned to receive either mefenamic acid $500 \mathrm{mg}$ tid (group A- 24 patients) or tranexamic acid 1 gm TID (group B- 26 patients) from day one to day five for three consecutive menstrual cycles.

Results: Reduction in menstrual blood loss as assessed by pictoral blood loss assessment chart was more in group B $(50 \%)$ than in Group A $(30 \%)$ (ANOVA, covariates with $\mathrm{F}=59.647, \mathrm{p}<0.001)$. Difference in improvement of dysmenorrhoea was not statistically significant $(\mathrm{p}=0.640)$. Side effects were less in group B compared to group A $(p=0.271)$. Post treatment $\mathrm{Hb} \%$ significantly improved in both groups $(p=0.015$ in group $A, p<0.001$ in gr $B)$. Acceptability was statistically similar in both groups ( $\mathrm{p}>0.05)$.

Conclusions: Both mefenamic acid and tranexamic acid were effective in management of menorrhagia. Tranexamic acid was significantly superior to mefenamic acid in terms of reduction in menstrual blood loss.
\end{abstract}

Keywords: Menorrhagia, Mefenamic acid, Pictoral blood loss assessment chart, Tranexamic acid

\section{INTRODUCTION}

Menorrhagia is an important healthcare problem in women. Menorrhagia is regular but heavy menstrual bleeding objectively defined as menstrual blood loss more than $80 \mathrm{ml}$. Objective assessment of menstrual blood loss by alkaline haematin method is the best method available for menstrual blood loss. But it uses specialised and time consuming techniques which are not available for routine clinical use. In an attempt to create a more accurate, yet simple method of assessment, a pictoral blood loss assessment chart (PBAC) was devised by Higgham et al which corresponds well with objective measurement of blood loss which was easy to use and has a role in monitoring the treatment of menorrhagia.
Pictoral score of 100 or more when used as a diagnostic test for menorrhagia was found to have a specificity and sensitivity of more than $80 \% .^{1-3}$ Once a baseline score has been established, subsequent treatment cycles are being assessed in same way and effectiveness assessed by a decreasing score. Studies using PBAC score for monitoring treatment of menorrhagia has been reported. ${ }^{4,5}$

Mechanism controlling menstrual bleeding is poorly understood. Heavy but regular menstrual bleeding can be encountered in ovulating women. In the absence of specific pathological cause, it is presumed that this reflects subtle disturbances in endometrial tissue mechanism. In the past decade, studies have shown increased endometrial fibrinolysis and an alteration in 
prostaglandin balance as local uterine abnormalities causing menorrhagia. These observations provide the rationale basis of treatment. ${ }^{6}$ Tranexamic acid is most commonly used antifibrinolytic drug and mefenamic acid is most commonly used non-steroidal antiinflammatory drug (NAID) used in management of menorrhagia. ${ }^{7,8}$

This study was conducted to compare the efficacy of mefenamic acid, an NSAID and tranexamic acid, an antifibrinolytic agent in the management of menorrhagia.

\section{METHODS}

One year study of women attending outpatient department of St. Philomena's Hospital, Bangalore with complaints of menorrhagia was conducted.

\section{Inclusion criteria}

Patients in the age group of 18 to 45 years with complaints of menorrhagia were evaluated. Menstrual blood loss was assessed by pictorial blood loss assessment chart (PBAC). Patients with PBAC score of more than 100, normal pelvic examination, normal cervical cytology were selected for the study.

\section{Exclusion criteria}

Patients with irregular menstrual cycles, symptoms of inter menstrual bleeding, spotting were not included for the study. Patients with organic pathology like fibroids, pelvic inflammation, and malignancy were excluded from the study. Also patients with renal impairment, thromboembolic conditions, peptic ulcers and patients on hormone therapy within past three months were excluded from the study.

Patients with complaints of menorrhagia were completely evaluated by a complete medical history, systemic and pelvic examination. Menstrual blood loss was assessed by PBAC in one pre-treatment control cycle. Pretreatment investigations included $\mathrm{Hb} \%$, $\mathrm{PCV}$, platelet count, blood group and Rh typing, BT, CT, pelvic ultrasound, PAP smear. Endometrial biopsy was considered in patients aged more than 40 yrs. Any organic pathology detected by pelvic examination, ultrasound, Pap smear and endometrial biopsy were excluded from the study.

54 patients were qualified for the study after meeting inclusion and exclusion criteria. They were allocated to either of the two treatments, mefenamic acid (Group A) or tranexamic acid (Group B) by a computer generated randomization chart (source: www.randomization.com, key10021).

Patients allocated to Group A received mefenamic acid $500 \mathrm{mg}$ TID from day one to day five. Patients allocated to Group B received tranexamic acid $1 \mathrm{gm}$ TID from day one to day five of menstrual cycle for three consecutive cycles. All patients recruited for the study were instructed to use the similar brand and size of sanitary pad available in pharmacy at St. Philomena's Hospital (trust me, regular size). They were educated about pictoral blood loss assessment chart (score 1 was given for lightly soiled pad, score 5 was given for moderately soiled pad and score 20 for heavily soiles pad, score 1 for $25 \mathrm{p}$ coin and score 5 for 1re coin) and were instructed to note the number of pads, staining pattern and the clots as per pictoral blood loss assessment chart. They were instructed to visit outpatient department every month and PBAC scoring was done each month. Symptoms like dysmenorrhoea, any side effects to treatment were enquired. At the end of three treatment cycles, average reduction in PBAC score was calculated. Women with dysmenorrhoea were asked for any improvement or worsening of dysmenorrhoea during the treatment cycles. $\mathrm{Hb} \%$ was measured at initial visit and at the end of three cycles in the same lab and difference in $\mathrm{Hb} \%$ was recorded.

Incidence of side effects attributable to the treatment cycles were assessed at each visit and various side effects were recorded.

\section{RESULTS}

Of 54 patients recruited for the study, with randomisation, 26 patients were in mefenamic acid (group A) group and 28 patients were in tranexamic acid (group B) group. Four patients were lost for follow up (two in mefenamic acid and two in tranexamic acid group) and did not provide any data. Hence 50 patients were included in the study with an intention to treat and analyse the outcome.

\section{Study design and statistical methods}

A comparative study consisting of 50 patients complaining of menorrhagia randomized into two groups24 patients in group A (mefenamic acid) and 26 patients in group B (tranexamic acid) was undertaken to know the efficacy, acceptability and safety of two drugs.

Table 1: Age distribution.

\begin{tabular}{|llll|}
\hline Age in years & $\begin{array}{l}\text { Group A } \\
(\mathbf{n = 2 4})\end{array}$ & $\begin{array}{l}\text { Group B } \\
(\mathbf{n = 2 6})\end{array}$ & $\begin{array}{l}\text { Total } \\
(\mathbf{n}=50)\end{array}$ \\
\hline $18-25$ & $7(29.17)$ & $8(30.76)$ & $15(30.00)$ \\
\hline $26-30$ & $8(33.33)$ & $7(26.92)$ & $15(30.00)$ \\
\hline $31-35$ & $4(16.67)$ & $5(19.23)$ & $9(18.00)$ \\
\hline $36-40$ & $4(16.67)$ & $5(19.23)$ & $9(18.00)$ \\
\hline$>40$ & $1(4.16)$ & $1(3.84)$ & $2(4.00)$ \\
\hline Mean \pm SD & $28.67 \pm 6.83$ & $29.54 \pm 6.38$ & $29.12 \pm 6.55$ \\
\hline Inference & $\begin{array}{l}\text { Age in years is comparable between two } \\
\text { groups with p=0.643 }\end{array}$ \\
\hline
\end{tabular}

Chi-square and Fisher test were used to find the significance of homogeneity of samples between group A and group B. Student paired t-test was used to find the 
significance of PBAC score and haemoglobin within each group and ANOVA was used to find the significance difference of PBAC scores between group A and group B.

Distribution in age, parity and duration of menorrhagia was comparable between the two groups (Table 1-3).

Table 2: Parity distribution.

\begin{tabular}{|llll|}
\hline Parity & $\begin{array}{l}\text { Group A } \\
(\mathrm{n}=24)\end{array}$ & $\begin{array}{l}\text { Group B } \\
(\mathrm{n}=26)\end{array}$ & $\begin{array}{l}\text { Total } \\
(\mathrm{n}=50)\end{array}$ \\
\hline Nullipara & $4(16.67)$ & $8(30.76)$ & $12(24.00)$ \\
\hline Para1 & $3(12.50)$ & $5(19.23)$ & $8(16.00)$ \\
\hline Para2 & $10(41.67)$ & $7(26.92)$ & $17(34.00)$ \\
\hline Para3 & $6(25.00)$ & $3(11.54)$ & $9(18.00)$ \\
\hline $\begin{array}{l}\text { Para4 and } \\
\text { above }\end{array}$ & $1(4.17)$ & $3(11.54)$ & $4(8.00)$ \\
\hline Inference & $\begin{array}{l}\text { Parity distribution in both the group is } \\
\text { comparable with } \mathrm{P}=0.368\end{array}$ \\
\hline
\end{tabular}

Table 3: Duration of menorrhagia.

\begin{tabular}{|llll|}
\hline $\begin{array}{l}\text { Duration of } \\
\text { Mennorhagia }\end{array}$ & $\begin{array}{l}\text { Group A } \\
(\mathbf{n = 2 4})\end{array}$ & $\begin{array}{l}\text { Group B } \\
(\mathbf{n = 2 6})\end{array}$ & $\begin{array}{l}\text { Total } \\
(\mathbf{n}=50)\end{array}$ \\
\hline$\leq 3$ months & $7(29.16)$ & $8(30.76)$ & $15(30.00)$ \\
\hline $4-6$ months & $6(25.00)$ & $8(30.76)$ & $14(28.00)$ \\
\hline $7-12$ months & $7(29.16)$ & $7(26.92)$ & $14(28.00)$ \\
\hline$>12$ months & $4(16.67)$ & $3(11.54)$ & $7(14.00)$ \\
\hline \multicolumn{4}{|l}{$\begin{array}{l}\text { Inference } \\
\text { Duration of mennorrhagia is } \\
\text { comparable between the two groups } \\
\text { with } \mathrm{P}=0.937\end{array}$} \\
\hline
\end{tabular}

Pretreatment mean PBAC score in group A was 150.67 and in group B was 163.69. Mean PBAC scores in treated cycles in group A during cycle one, two and three were $101.54,105.04$ and 101.42 respectively.

Table 4: Reduction in Menstrual Blood Loss.

\begin{tabular}{|c|c|c|}
\hline $\begin{array}{l}\text { PBAC score } \\
(\text { Mean } \pm \text { SD) }\end{array}$ & $\begin{array}{l}\text { Group A } \\
(\mathrm{n}=24)\end{array}$ & $\begin{array}{l}\text { Group B } \\
(\mathrm{n}=26)\end{array}$ \\
\hline $\begin{array}{l}\text { Pre treatment } \\
\text { cycle }\end{array}$ & $150.67 \pm 19.76$ & $163.69 \pm 30.28$ \\
\hline \multicolumn{3}{|l|}{ Treated cycles } \\
\hline Cycle 1 & $101.54 \pm 25.43$ & $85.38 \pm 22.43$ \\
\hline Cycle 2 & $105.04 \pm 18.95$ & $88.46 \pm 22.57$ \\
\hline Cycle 3 & $101.42 \pm 29.92$ & $84.42 \pm 23.46$ \\
\hline $\begin{array}{l}\text { Average of } 3 \\
\text { cycles }\end{array}$ & $104.04 \pm 17.72$ & $82.20 \pm 11.88$ \\
\hline Significance & $\begin{array}{l}\text { Student } \mathrm{t}=14.250, \\
\mathrm{p}<0.001\end{array}$ & $\begin{array}{l}\text { Student } \mathrm{t}=22.865, \\
\mathrm{p}<0.001\end{array}$ \\
\hline Effect Size & 2.48 & 3.87 \\
\hline $\begin{array}{l}\text { Significance } \\
\text { by ANOVA }\end{array}$ & \multicolumn{2}{|c|}{$\begin{array}{l}\text { PBAC score is significantly reduced } \\
\text { in group B when compared to group A } \\
\text { keeping pre scores as covariates with } \\
\mathrm{F}=59.647, \mathrm{P}<0.001\end{array}$} \\
\hline
\end{tabular}

Mean PBAC score in treated cycles in group B during cycle one, two and three were $85.38,88.46$, and 84.42 respectively. When average of three treated cycles were taken mean PBAC score was 104.04 in group A and 82.20 in group B (Table 4).

There was $31 \%$ reduction in PBAC score in group A and $50 \%$ reduction in group $\mathrm{B}$. Of patients in group $\mathrm{B}, 23$ patients had PBAC score of less than 100 and of group A, 9 patients had PBAC score of less than 100 after treatment. As there was significant difference in mean PBAC score between the two groups in pretreatment cycle, significance was calculated by applying ANOVA keeping the pretreatment scores as covariates. PBAC score was significantly reduced in group B compared to group A with $\mathrm{p}<0.001$ (Table 4).

Dysmenorrhoea was present in 11 of 24 patients in group A, 12 of 26 patients in group B. During treatment, improvement in dysmenorrhoea was reported by 9 of 11 patients in group A (81.85\%), 8 of 12 patients in group B $(61.66 \%) .2$ patients in group A and 4 patients in group neither had improvement or nor worsening. There was no worsening of dysmenorrhoea in either of two groups. Difference in improvement of dysmenorrhoea was not statistically significant between group A and group B $(\mathrm{p}=0.640)$.

Side effects were reported by 12 patients in group A and 9 patients in group B. Side effects reported included epigastric pain, nausea, vomiting, and giddiness. When the incidence of side effects were compared between two groups, it was significantly less in group $B(p=0.271)$ (Table 5).

Mean $\mathrm{Hb} \%$ in pre-treatment cycle was $10.41 \mathrm{gm} \%$ in group A, and $9.88 \mathrm{gm} \%$ in group B. At the end of three treatment cycles mean $\mathrm{Hb} \%$ was $11.35 \%$ and $10.70 \%$ in group A and group B respectively. Improvement in $\mathrm{Hb} \%$ was present in 19 patients in group A and 23 patients in group B. Thus $\mathrm{Hb} \%$ improved significantly in both groups with $\mathrm{p}$ value of 0.015 in group $\mathrm{A}$ and $<0.001$ in group B.

\section{Table 5: Side effects.}

\begin{tabular}{|llll|}
\hline Side effects & $\begin{array}{l}\text { Group A } \\
(\mathbf{n}=24)\end{array}$ & $\begin{array}{l}\text { Group B } \\
(\mathbf{n}=26)\end{array}$ & $\begin{array}{l}\text { Total } \\
(\mathbf{n}=50)\end{array}$ \\
\hline Present & $12(50.0)$ & $9(34.62)$ & $21(42.00)$ \\
\hline Absent & $12(50.0)$ & $17(65.38)$ & $29(58.00)$ \\
\hline Inference & $\begin{array}{l}\text { Side effects are less in Group B with } \\
\mathrm{P}=0.271\end{array}$ \\
\hline
\end{tabular}

20 out of 24 patients in group A and 23 out 26 patients in group B reported significant improvement in lifestyle in terms of improvement of dysmenorrhoea, decreased flooding, improvement in participation in social activities and willing to continue treatment. They found the treatment was acceptable. 4 patients in group A were not willing to continue ( 3 patients because of more side effects and 1 patient because of unsatisfaction in 
reduction in blood flow). 3 patients in group B were not willing to continue because of side effects.

There were 2 patients in group A and 4 patients in group $B$ with Intrauterine Contraceptive Devices (IUCD). There was reduction in PBAC score by 47 in group $A$ and by 72 in group B. As sample size of IUCD users was small, no conclusion could be drawn.

\section{DISCUSSION}

The present study compares the use of two non-hormonal drugs used in medical management of menorrhagia in terms of reduction of menstrual blood loss, improvement in dysmenorrhoea, incidence of adverse effects, improvement in $\mathrm{Hb} \%$ and improvement of quality of life as reflected by acceptance of treatment.

The present study shows that there is significant reduction in menstrual blood loss both with Tranexamic acid and mefenamic acid, but tranexamic acid proved to be more efficacious. Average mean PBAC scored decreased by $31 \%$ in mefenamic acid group and by $50 \%$ in tranexamic acid. This was in accordance with previous studies. Cameron et al compared mefenamic acid with norethisterone in 32 patients with ovulatory menorrhagia and found a reduction in menstrual blood loss by $24 \%$ in mefenamic acid group and $20 \%$ reduction in norethisterone group. ${ }^{9}$

Peterson et al compared the efficacy of tranexamic acid and norethisterone in management of ovulatory menorrhagia, 25 patients received tranexamic acid, 21 patients received norethisterone. ${ }^{10}$ They found $45 \%$ reduction in menstrual blood loss with tranexamic acid and $20 \%$ reduction in menstrual blood loss with norethisterone. Bonnar et al compared efficacy of ethamsylate, mefenamic acid, tranexamic acid for treating menorrhagia in a randomised trial and found reduction in menstrual blood loss by $20 \%$ in ethamsylate group, $31 \%$ reduction in mefenamic acid group, 54\% reduction in tranexamic acid group. ${ }^{11}$ Lee et al compared the efficacy of tranexamic acid for essential menorrhagia. ${ }^{4}$

11 patients were with menorrhagia were treated with tranexamic acid $1 \mathrm{gm} 6$ hourly for 3-4 days (day 1 to day 3 ) and there was reduction in menstrual blood loss by $54 \%$. Peter et al compared the efficacy of LNG-IUS with mefenamic acid in 51 patients in terms of reduction in menstrual blood loss, PBAC score, total menstrual fluid loss, 25 were randomised to receive LNG-IUS and 26 to receive oral mefenamic acid. ${ }^{5}$ They found a mean reduction of PBAC score of $37 \%$ in mefenamic acid and 95\% in LNG-IUS. Most of the previous studies used alkaline haematin method for menstrual blood loss assessment, but this is cumbersome and time consuming procedure and is not available in clinical practice in most set up. Hence a simple but more accurate method of pictoral blood loss assessment chart which has sensitivity and specificity of more than $80 \%$ was used in the study.
Few of the previous studies do have used pictoral blood loss assessment chart.

In terms of improvement in dysmenorrhoea, the present study showed an improvement rate of $88 \%$ in Mefenamic acid $66 \%$ in tranexamic acid group. Dockeray et $\mathrm{al}^{12}$ in comparison of mefenamic acid with danazol in 40 patients with menorrhagia found an improvement rate of $77 \%$ in patients treated with mefenamic acid. Bonnar et $\mathrm{al}^{11}$ in comparative study of ethamsylate, tranexamic acid, mefenamic acid show improvement in dysmenorrhoea in $4 \%, 9 \%, 13 \%$ in patients treated with ethamsylate, tranexamic acid and mefenamic acid respectively.

The present study showed a mean increase in $\mathrm{Hb} \%$ of $9 \%$ in mefenamic acid group, and $8.3 \%$ in tranexamic acid group. Lee et al reported $7.7 \%$ increase in mean $\mathrm{Hb} \%$ with tranexamic acid for menorrhagia. ${ }^{4}$ Gleeson et al reported $9.1 \%$ increase in mean $\mathrm{Hb} \%$ I patients who received tranexamic acid for menorrhagia. ${ }^{13}$

\section{CONCLUSION}

Both mefenamic acid and tranexamic acid were effective in management of menorrhagia. Tranexamic acid was superior to mefenamic acid in terms of reduction in menstrual blood loss. Both have the advantage of only being taken during menstruation. Control of dysmenorrhoea was achieved in significant number of patients in both groups. Minor side effects like epigastric pain, nausea, vomiting was more frequent in mefenamic acid group. Acceptability rate was high in both groups.

\section{ACKNOWLEDGMENTS}

Authors would like to thank Dr Shylaja AS, Dr Chopde SS, Dr Venkatesh N for their support during this study. Authors also acknowledge Mr. K P Suresh for his immense help.

\section{Funding: No funding sources}

Conflict of interest: None declared

Ethical approval: The study was approved by the Institutional Ethics Committee

\section{REFERENCES}

1. Week AD SRG. Duff Abnormal uterine bleeding Diagnosis and medical management. Progress in obstetrics and Gynecology by John Studd; 1996;12:309-23.

2. Chimbiria TH, Anne Anderson ABM, Turnbull AC. Relation between measured menstrual blood loss and patients subjective assessment of loss, duration of bleeding, number of sanitary towel used, uterine weight and endometrial surface are. $\mathrm{Br} \mathrm{J}$ Obstet Gynecol. 1980;87:603-9.

3. Higham JM. Medical treatment of menorrhagia. Progress in obstetrics and gynaecology by John Studd; 1991;9:335-348. 
4. Joseph Lee Y, Philip Hahn M, Janice Van P, Robert Reid L. Treatment of menorrhagia with Tranexamic acid. J Soc Obstet Gynaecol Can. 2000;22(10):794-8.

5. Winkler UH. Effect of Tranexamic acid on quality of life in women with heavy menstrual bleeding. Eur J Obstet Gynaecol Reprod Biol. 2001;99(2):238-43.

6. Prentice A. Fortnightly review. Medical management of menorrhagia. Br Med J. 1999;1343-5.

7. Reid PC. Randomised comaritive trial of Lng IUS and Mefenamic acid in management of menorrhagia, multiple analysis using menstrual blood loss, pictoral blood loss assessment charts. Cochrane Library, Cochrane Database Syst Rev. 2005;4.

8. Rybo G. Tranexamic acid therapy. Effective treatment in menstrual bleeding, Clinical update on safety. Therapeutic Advances. 1991;(4):41-8.

9. Ian CT, Lumsden MA, Stephen SK. Effect of Mefenamic acid and Norethisterone in measured menstrual blood loss. Obstet Gynecol. 1990;76(85):85-8.

10. Preston JT, Cameron IT, Adams EJ, Smith SK. Comparative study of Tranexamic acid and
Norethisterone. In treatment of ovulatory menorrhagia. Br J Obstet Gynaecol. 1995;102:401-6.

11. Bonnar J, Brian SL. Treatment of menorrhagia during menstruation. Randomised controlled trial of Ethamsylate Mefenamic acid and Tranexamic acid. British Med J. 1996;313:579-82.

12. Dockeray CJ, Sheppard BL, Bonnar J. Comparison between Mefenamic acid and Danazol in treatment of established menorrhagia. Br J Obstetr Gynecol. 1989;96:840-4.

13. Gleeson NC, Buggy F, Sheppard BL, Bonnar J. The effects of Tranexamic acid on measured menstrual loss and endometrial fibrinolytic enzymes in dysfunctional uterine bleeding. Acta Obstet Gynecol Scand. 1994;73(3):274-7.

Cite this article as: Madhu J, Shylaja AS. Randomised trial of mefenamic acid versus tranexamic acid in management of menorrhagia. Int J Reprod Contracept Obstet Gynecol 2017;6:4608-12. 